\title{
Practitioner Review: Psychosocial Treatments for Conduct Disorder in Children
}

\author{
Alan E. Kazdin \\ Yale University, New Haven, U.S.A.
}

\begin{abstract}
The present paper reviews promising treatments for conduct disorder among children and adolescents. The treatments include problem-solving skills training, parent management training, functional family therapy and multisystemic therapy. For each treatment, conceptual underpinnings, characteristics and outcome evidence are highlighted. Limitations associated with these treatments (e.g. paucity of long-term follow-up evidence and of evidence for the clinical significance of the change) are also presented. Broader issues that affect treatment and clinical work with conduct-disordered youths are also addressed, including retaining cases in treatment, what treatments do not work, who responds well to treatment, comorbidity, the use of combined treatments and the need for new models of treatment delivery.
\end{abstract}

Keywords: Conduct disorder, treatment, children and adolescents, therapy.

Abbreviations: ADHD: Attention Deficit/Hyperactivity Disorder;CD: Conduct Disorder; FFT: functional family therapy; MST: multisystemic therapy; ODD: Oppositional Defiant Disorder; PMT: parent management training; PSST : problem-solving skills training.

Antisocial behaviors in children refer to a variety of acts that reflect social rule violations and that are actions against others. Behaviors such as fighting, lying and stealing are seen in varying degrees in most children over the course of development. For present purposes, the term conduct disorder will be used to refer to antisocial behavior that is clinically significant and clearly beyond the realm of "normal" functioning. The extent to which antisocial behaviors are sufficiently severe to constitute conduct disorder depends on several characteristics of the behaviors including their frequency, intensity and chronicity, whether they are isolated acts or part of a larger syndrome with other deviant behaviors, and whether they lead to significant impairment of the child as judged by parents, teachers or others.

Little in the way of effective treatment has been generated for conduct disorder. This is unfortunate in light of the personal tragedy that conduct disorder can represent to children and their families and others who may be victims of aggressive and antisocial acts. From a social perspective, the absence of effective treatments is problematic as well. Conduct disorder is one of the most frequent bases of clinical referral in child and adolescent treatment services, has relatively poor long-term prognosis and is transmitted across generations (see Kazdin,

Requests for reprints to: Alan E. Kazdin, Department of Psychology, Yale University, PO Box 208205, New Haven, CT 06520-8205, U.S.A. (E-mail Kazdin@Minerva.cis.yale.edu). 1995b). Because children with conduct disorder often traverse multiple social services (e.g. special education, mental health, juvenile justice) the disorder is one of the most costly mental disorders in the United States (Robins, 1981).

There have been significant advances in treatment. The present paper reviews research for four psychosocial treatments that have shown considerable promise in the treatment of conduct disorder in children and adolescents. ("Children" will be used to refer to both children and adolescents, unless a particular distinction is made between the two.) The treatments were selected because they have been carefully evaluated in controlled clinical trials. The paper describes and evaluates the underpinnings, techniques and evidence on behalf of these treatments. Critical issues that are raised in providing treatment to conduct disorder children and their families are also examined.

\section{Overview of Characteristics of Conduct Disorder}

Before discussing treatment of conduct disorder, it is important to delineate the "problem" as it is often presented clinically. From a treatment perspective, conduct disorder represents a very broad domain involving child, parent, family and contextual conditions. Many of the factors that influence delivery and effectiveness of treatment are not encompassed by the central diagnostic features of the disorder. Next we will consider briefly some salient domains that are relevant to treatment. 


\section{Central Features}

The overriding feature of conduct disorder is a persistent pattern of behavior in which the rights of others and age-appropriate social norms are violated. Isolated acts of physical aggression, destruction of property, stealing and firesetting are sufficiently severe to warrant concern and attention in their own right. Although these behaviors may occur in isolation, several of these are likely to appear together as a constellation or syndrome and form the basis of a clinical diagnosis. For example, in the Diagnostic and Statistical Manual of Mental Disorders (DSM-IV; American Psychiatric Association, 1994), the diagnosis of Conduct Disorder (CD) is reached if the child shows at least 3 of the 15 symptoms within in the past 12 months, with at least 1 symptom evident within the past 6 months. The symptoms include: bullying others, initiating fights, using a weapon, being physically cruel to others or to animals, stealing while confronting a victim, firesetting, destroying property, breaking into others' property, stealing items of nontrivial value, staying out late, running away, lying, deliberate firesetting and truancy.

It is important to retain the distinction between conduct disorder as a general pattern of behavior and the diagnosis of $\mathrm{CD}$. The general pattern of conduct disorder behavior has been studied extensively using varied populations (e.g. clinical referrals and delinquent samples) and defining criteria (Kazdin, 1995b). There is widespread agreement and evidence that a constellation of antisocial behaviors can be identified and has correlates related to child, parent and family functioning. Moreover, antisocial behaviors included in the constellation extend beyond those recognized in diagnosis (e.g. substance abuse, associating with delinquent peers).

\section{The Scope of Dysfunction}

If one were to consider "only" the symptoms of conduct disorder and the persistence of impairment, the challenge of identifying effective treatments would be great enough. However, the presenting characteristics of children and their families usually raise a number of other considerations that are central to treatment. Consider next the characteristics of children, parents, families and contexts that are associated with conduct disorder, as a backdrop for later comments on treatment.

Child characteristics. Children who meet criteria for $\mathrm{CD}$ are likely to meet criteria for other disorders as well. The coexistence of more than one disorder is referred to as comorbidity. In general, diagnoses involving disruptive or externalizing behaviors (CD, Oppositional Defiant Disorder [ODD], and Attention Deficit/Hyperactivity Disorder [ADHD]) often go together. In studies of community and clinic samples, a large percentage of youth with $\mathrm{CD}$ or $\mathrm{ADHD}$ (e.g. $45-70 \%$ ) also meet criteria for the other disorder (e.g. Fergusson, Horwood \& Lloyd, 1991; Offord, Boyle \& Racine, 1991). The cooccurrence of $\mathrm{CD}$ and ODD is common as well. Among clinic-referred youth who meet criteria for $C D, 84-96 \%$ also meet concurrent diagnostic criteria for ODD (see
Hinshaw, Lahey \& Hart, 1993). ${ }^{1} \mathrm{CD}$ is sometimes comorbid with anxiety disorders and depression (Hinshaw et al., 1993; Walker et al., 1991).

Several other associated features of $C D$ are relevant to treatment. For example, children with conduct disorder are also likely to show academic deficiencies, as reflected in achievement level, grades, being left behind in school, early termination from school and deficiencies in specific skill areas such as reading. Youths with the disorder are likely to evince poor interpersonal relations, as reflected in diminished social skills in relation to peers and adults and higher levels of peer rejection. Conduct disorder youths also are likely to show a variety of cognitive and attributional processes. Deficits and distortions in cognitive problem-solving skills, attributions of hostile intent to others, and resentment and suspiciousness, illustrate a few cognitive features associated with conduct disorder.

Parent and family characteristics. Several parent and family characteristics are associated with conduct disorder (see Kazdin, 1995b; Robins, 1991; Rutter \& Giller, 1983). Criminal behavior and alcoholism are two of the stronger and more consistently demonstrated parental characteristics. Parent disciplinary practices and attitudes, especially harsh, lax, erratic and inconsistent discipline practices, often characterize the parents. Dysfunctional relations are also evident, as reflected in less acceptance of their children, less warmth, affection and emotional support, and less attachment, compared to parents of nonreferred youth. Less supportive and more defensive communications among family members, less participation in activities as a family and more clear dominance of one family member are also evident. In addition, unhappy marital relations, interpersonal conflict and aggression characterize the parental relations of antisocial children. Poor parental supervision and monitoring of the child and knowledge of the child's whereabouts are also associated with conduct disorder.

Contextual conditions. Conduct disorder is associated with a variety of untoward living conditions such as large family size, overcrowding, poor housing, and disadvantaged school settings (see Kazdin, 1995b). Many of the untoward conditions in which families live place stress on the parents or diminish their threshold for coping with everyday stressors. The net effect can be evident in parent-child interaction in which parents inadvertently engage in patterns that sustain or accelerate antisocial and aggressive interactions (e.g. Dumas \& Wahler, 1983; Patterson, Capaldi \& Bank, 1991).

Quite often the child's dysfunction is embedded in a larger context that cannot be neglected in conceptual views about the development, maintenance and course of conduct disorder nor in the actual delivery of treatment. For example, at our outpatient clinical service (Yale Child Conduct Clinic), it is likely that a family referred for treatment will experience a subset of these characteristics: financial hardship (unemployment, significant debt, bankruptcy), untoward living conditions (danger-

\footnotetext{
1 In DSM-IV, if the child meets criteria for CD, ODD is not diagnosed, because the former is likely to include many symptoms of the latter. Yet, invoking and evaluating the criteria for these diagnoses ignoring this consideration has been useful in understanding the relation and overlap of these diagnoses.
} 
ous neighborhood, small living quarters), transportation obstacles (no car or car in frequent repair, state provided taxi service), psychiatric impairment of one of the parents, stress related to significant others (former spouses, boyfriends or girlfriends) and adversarial contact with an outside agency (schools, youth services, courts). Conduct disorder is conceived as a dysfunction of children and adolescents. The accumulated evidence regarding the symptom constellation, risk factors, and course over childhood, adolescence and adulthood attests to the heuristic value of focusing on individual children. At the same time, there is a child-parent-family-context gestalt that includes multiple and reciprocal influences that affect each participant (child and parent) and the systems in which they operate (family, school) (Kazdin, 1993). For treatment to be effective, it is likely that multiple domains will have to be addressed.

\section{Promising Treatment Approaches}

\section{Overview: Criteria for Identifying Promising Treat- ments}

Many different treatments have been applied to conduct-disordered youths, including psychotherapy, pharmacotherapy, psychosurgery, home, school and community-based programs, residential and hospital treatment, and social services (see Brandt \& Zlotnick, 1988; Dumas, 1989; Kazdin, 1985; United States Congress, 1991). Of the over 230 documented psychotherapies available for children and adolescents (Kazdin, 1988), the vast majority have not been studied. Among those that have, none has been shown to controvert conduct disorder and its long-term course. Many treatments might seem conceptually justified as interventions for conduct disorder. Conduct disorder is a dysfunction with pervasive features so that one can point to virtually any domain (e.g. psychodynamics, family interaction patterns, cognitive deficiencies) and find aberrations, deficits and deficiencies.

In our own work, we have relied on several criteria (please see Table 1) to identify and to select promising treatments among the array of available interventions. The initial criterion is that the treatment should have some theoretical rationale that notes how the dysfunction, in this case conduct disorder, comes about and then how treatment redresses the dysfunction. Specification of the mechanisms leading to conduct disorder and leading to therapeutic change are required for this initial criterion.

The second criterion considers whether there is any basic research to support the conceptualization. Basic research in this context refers to studies that examine conduct problems and factors that lead to their onset, maintenance, exacerbation, amelioration or attenuation. An example would be studies of the family that demonstrate specific interaction patterns among parents and children that exacerbate aggression within the home (Patterson, Reid \& Dishion, 1992). Such research would advance considerably the conceptual view that posited the significance of these patterns and provided a warrant for treatments that are aimed at these interaction patterns.

The third criterion is whether there is any outcome
Table 1

Criteria for Identifying Promising Treatments

1. CONCEPTUALIZATION

Theoretical statement relating the mechanism(s) (e.g. intrapsychic, intrafamilial) to clinical dysfunction

2. BASIC RESEARCH

Evidence showing that the mechanism can be assessed and relates to dysfunction, independently of treatment outcome studies

3. PRELIMINARY OUTCOME EVIDENCE

Evidence in analogue or clinical research showing that the approach leads to change on clinically relevant measures

4. PROCESS-OUTCOME CONNECTION

Evidence in outcome studies showing a relationship between the change in processes alleged to be operative and clinical outcome

evidence that the treatment can effect change. In canvassing the literature, we tend to be very lenient for invoking this criterion; we are interested in any demonstration (e.g. so-called open trials, studies with mildly disturbed cases). Obviously, randomized controlled clinical trials are preferred. However, the vast majority of treatments available for children and adolescents have never been tested in any controlled or uncontrolled trial (Kazdin, 1988). Understandably, we are encouraged if there is a crumb of data showing that someone changed somewhere after exposure to treatment.

Finally, evidence from an outcome study that shows a relation between these processes hypothesized to be critical to therapeutic change and actual change would be very persuasive. Assessment of processes might be reflected in cognitions, family interaction or core conflicts and defenses. Therapeutic change would be shown to covary with the extent to which these processes were altered in treatment. This latter criterion is very demanding indeed and perhaps is better conceived as a goal toward which we strive rather than a point of departure for identifying promising treatments.

No single treatment among those available adequately traverses all of these criteria. Yet, a number of promising treatments have been identified for conduct disorder. Four treatment approaches with evidence on their behalf are illustrated next. In highlighting the approaches, the purpose is not to convey that only four promising treatments exist. However, these four are clearly among the most well developed in relation to the criteria highlighted here and the number of controlled clinical trials. $^{2}$

\section{Cognitive Problem-solving Skills Training}

Background and underlying rationale. Cognitive processes refer to a broad class of constructs that pertain to how the individual perceives, codes and experiences the world. Individuals who engage in conduct disorder

\footnotetext{
2 The rationale, empirical underpinnings, outcome research and treatment procedures cannot be fully elaborated for each of the techniques. References will be made to reviews of the evidence and to treatment manuals that elaborate each of the treatments.
} 
behaviors, particularly aggression, have been found to show distortions and deficiencies in various cognitive processes. These deficiencies are not merely reflections of intellectual functioning. Although selected processes (recall, information processing) are related to intellectual functioning, their impact has been delineated separately and shown to contribute to behavioral adjustment and social behavior.

A variety of cognitive processes have been studied, such as generating alternative solutions to interpersonal problems (e.g. different ways of handling social situations), identifying the means to obtain particular ends (e.g. making friends) or consequences of one's actions (e.g. what could happen after a particular behavior); making attributions to others of the motivation of their actions; perceiving how others feel; expectations of the effects of one's own actions and others (see Shirk, 1988; Spivack \& Shure, 1982). Deficits and distortion among these processes relate to teacher ratings of disruptive behavior, peer evaluations and direct assessment of overt behavior (e.g. Lochman \& Dodge, 1994; Rubin, Bream \& Rose-Krasnor, 1991).

As an illustration, aggression is not merely triggered by environmental events, but rather through the way in which these events are perceived and processed. The processing refers to the child's appraisals of the situation, anticipated reactions of others and self-statements in response to particular events. For example, attribution of intent to others represents a salient cognitive disposition critically important to understanding aggressive behavior. Aggressive youths tend to attribute hostile intent to others, especially in social situations where the cues of actual intent are ambiguous (see Crick \& Dodge, 1994). Understandably, when situations are initially perceived as hostile, youths are more likely to react aggressively.

Although many studies have shown that conductdisordered youths experience various cognitive distortions and deficiencies, fundamental questions remain to be resolved. Among these questions are the specificity of cognitive deficits among diagnostic groups and youths of different ages, whether some of the processes are more central than others, and how these processes unfold developmentally. Nevertheless, research on cognitive processes among aggressive children has served as an heuristic base for conceptualizing treatment and for developing specific treatment strategies.

Characteristics of treatment. Problem-solving skills training (PSST) consists of developing interpersonal cognitive problem-solving skills. Although many variations of PSST have been applied to conduct problem children, several characteristics are usually shared. First, the emphasis is on how children approach situations, i.e. the thought processes in which the child engages to guide responses to interpersonal situations. The children are taught to engage in a step-by-step approach to solve interpersonal problems. They make statements to themselves that direct attention to certain aspects of the problem or tasks that lead to effective solutions. Second, behaviors that are selected (solutions) to the interpersonal situations are important as well. Prosocial behaviors are fostered (through modeling and direct reinforcement) as part of the problem-solving process. Third, treatment utilizes structured tasks involving games, academic ac- tivities and stories. Over the course of treatment, the cognitive problem-solving skills are increasingly applied to real-life situations. Fourth, therapists usually play an active role in treatment. They model the cognitive processes by making verbal self-statements, apply the sequence of statements to particular problems, provide cues to prompt use of the skills and deliver feedback and praise to develop correct use of the skills. Finally, treatment usually combines several different procedures including modeling and practice, role-playing, and reinforcement and mild punishment (loss of points or tokens). These are deployed in systematic ways to develop increasingly complex response repertoires of the child.

Overview of the evidence. Several outcome studies have been completed with impulsive, aggressive and conduct-disordered children and adolescents (see Baer \& Nietzel, 1991; Durlak, Furhman \& Lampman, 1991 for reviews). Cognitively based treatments have significantly reduced aggressive and antisocial behavior at home, at school and in the community. At follow-up, these gains have been evident up to one year later. Many early studies in the field (e.g. 1970s-80s) focused on impulsive children and nonpatient samples. Since that time, several studies have shown treatment effects with inpatient and outpatient cases (see Kazdin, 1993; Kendall, 1991; Pepler \& Rubin, 1991).

There is only sparse evidence that addresses the child, parent, family, contextual or treatment factors that influence treatment outcome. Some evidence suggests that older children profit more from treatment than do younger children, perhaps due to their cognitive development (Durlak et al., 1991). However, the basis for differential responsiveness to treatment as a function of age has not been well tested. Conduct-disordered children who show comorbid diagnoses, academic delays and dysfunction and lower reading achievement, and who come from families with high levels of impairment (parent psychopathology, stress and family dysfunction) respond less well to treatment than youths with less dysfunction in these domains (Kazdin, 1995a; Kazdin \& Crowley, in press). However, these child, parent and family characteristics may influence the effectiveness of several different treatments for conduct-disordered youths rather than PSST in particular. Much further work is needed to evaluate factors that contribute to responsiveness to treatment.

Overall evaluation. There are features of PSST that make it an extremely promising approach. Perhaps most importantly, several controlled outcome studies with clinic samples have shown that cognitively based treatment leads to therapeutic change. Second, basic research in developmental psychology continues to elaborate the relation of maladaptive cognitive processes among children and adolescents and conduct problems that serve as underpinnings of treatment (Crick \& Dodge, 1994; Shirk, 1988). Third and on a more practical level, many versions of treatment are available in manual form (e.g. Feindler \& Ecton, 1986; Finch, Nelson \& Ott, 1993; Shure, 1992). Consequently, the treatment can be evaluated in research and explored further in clinical practice.

Fundamental questions about treatment remain. To begin, the role of cognitive processes in clinical dysfunction and treatment warrant further evaluation. Evi- 
dence is not entirely clear, showing that a specific pattern of cognitive processes characterizes youths with conduct problems rather than adjustment problems more generally. Also, although evidence has shown that cognitive processes change with treatment, evidence has not established that change in these processes is correlated with improvements in treatment outcome. This means that the basis for therapeutic change has yet to be established. Also, characteristics of children and their families and parameters of treatment that may influence outcome have not been carefully explored in relation to treatment outcome. Clearly, central questions about treatment and its effects remain to be resolved. Even so, PSST is highly promising because treatment effects have been replicated in several controlled studies with conduct-disordered youth.

\section{Parent Management Training}

Background and underlying rationale. Parent management training (PMT) refers to procedures in which parents are trained to alter their child's behavior in the home. The parents meet with a therapist or trainer who teaches them to use specific procedures to alter interactions with their child, to promote prosocial behavior and to decrease deviant behavior. Training is based on the general view that conduct problem behavior is inadvertently developed and sustained in the home by maladaptive parent-child interactions. There are multiple facets of parent-child interaction that promote aggressive and antisocial behavior. These patterns include directly reinforcing deviant behavior, frequently and ineffectively using commands and harsh punishment, and failing to attend to appropriate behavior (Patterson, 1982; Patterson et al., 1992).

It would be misleading to imply that the parent generates and is solely responsible for the child-parent sequences of interactions. Influences are bidirectional, so that the child influences the parent as well (see Bell \& Harper, 1977; Lytton, 1990). Indeed, in some cases the children engage in deviant behavior to help prompt the interaction sequences. For example, when parents behave inconsistently and unpredictably (e.g. not attending to the child in the usual ways), the child may engage in some deviant behavior (e.g. whining, throwing some object). The effect is to cause the parent to respond in more predictable ways (see Wahler \& Dumas, 1986). Essentially, inconsistent and unpredictable parent behavior is an aversive condition for the child; the child's deviant behavior is negatively reinforced by terminating this condition. However, the result is also to increase parent punishment of the child.

Among the many interaction patterns, those involving coercion have received the greatest attention (Patterson et al., 1992). Coercion refers to deviant behavior on the part of one person (e.g. the child) that is rewarded by another person (e.g. the parent). Aggressive children are inadvertently rewarded for their aggressive interactions and their escalation of coercive behaviors, as part of the discipline practices that sustain aggressive behavior. The critical role of parent-child discipline practices has been supported by correlational research, relating specific discipline practices to child antisocial behavior, and by experimental research, showing that directly altering these practices reduces antisocial child behavior (see Dishion, Patterson \& Kavanagh, 1992).

The general purpose of PMT is to alter the pattern of interchanges between parent and child so that prosocial, rather than coercive, behavior is directly reinforced and supported within the family. This requires developing several different parenting behaviors, such as establishing the rules for the child to follow, providing positive reinforcement for appropriate behavior, delivering mild forms of punishment to suppress behavior, negotiating compromises and other procedures. These parenting behaviors are systematically and progressively developed within the sessions in which the therapist shapes (develops through successive approximations) parenting skills. The programs that parents eventually implement in the home also serve as the basis for the focus of the sessions in which the procedures are modified and refined.

Characteristics of treatment. Although many variations of PMT exist, several common characteristics can be identified. First, treatment is conducted primarily with the parent(s), who implement several procedures in the home. The parents meet with a therapist who teaches them to use specific procedures to alter interactions with their child, to promote prosocial behavior and to decrease deviant behavior. There is usually little direct intervention of the therapist with the child. With young children, the child may be brought into the session to help train both parent and child how to interact and especially to show the parent precisely how to deliver prompts (antecedents) and consequences (reinforcement, time out from reinforcement). Older youths may participate to negotiate and to develop behavior-change programs in the home. Second, parents are trained to identify, define and observe problem behaviors in new ways. Careful specification of the problem is essential for the delivery of reinforcing or punishing consequences and for evaluating if the program is achieving the desired goals. Third, the treatment sessions cover social learning principles and the procedures that follow from them including: positive reinforcement (e.g. the use of social praise and tokens or points for prosocial behavior), mild punishment (e.g. use of time out from reinforcement, loss of privileges), negotiation, and contingency contracting. Fourth, the sessions provide opportunities for parents to see how the techniques are implemented, to practise using the techniques, and to review the behavior-change programs in the home. The immediate goal of the program is to develop specific skills in the parents. As the parents become more proficient, the program can address the child's most severely problematic behaviors and encompass other problem areas (e.g. school behavior). Over the course of treatment, more complex repertoires are developed, both in the parents and the child. Finally, child functioning at school is usually incorporated into the program. Parent-managed reinforcement programs for child deportment and performance at school, completion of homework, activities in the playground and so on are often part of the behavior-change programs. If available, teachers can play an important role in monitoring or providing consequences for behaviors at school.

Overview of the evidence. PMT is one of the most wellresearched therapy techniques for the treatment of 
conduct-disordered youth. Scores of outcome studies have been completed with youths varying in age and degree of severity of dysfunction (e.g. oppositional, conduct disorder, delinquent youth) (see Kazdin, 1993; Miller \& Prinz, 1990; Patterson, Dishion \& Chamberlain, 1993). Treatment effects have been evident in marked improvements in child behavior on a wide range of measures including parent and teacher reports of deviant behavior, direct observation of behavior at home and at school and institutional (e.g. school, police) records. The effects of treatment have also been shown to bring problematic behaviors of treated children within normative levels of their peers who are functioning adequately in the community. Follow-up assessment has shown that the gains are often maintained 1-3 years after treatment. Longer follow-up assessment rarely takes place, although one program reported maintenance of gains 10-14 years later (Forehand \& Long, 1988; Long, Forehand, Wierson \& Morgan, 1994).

The impact of PMT is relatively broad. The effects of treatment are evident for child behaviors that have not been focused on directly as part of training. Also, siblings of children referred for treatment improve, even though they are not directly focused on in treatment. This is an important effect because siblings of conduct-disordered youths are at risk for severe antisocial behavior. In addition, maternal psychopathology, particularly depression, has been shown to decrease systematically following PMT (see Kazdin, 1985). These changes suggest that PMT alters multiple aspects of dysfunctional families.

Several characteristics of the treatment contribute to outcome. Duration of treatment appears to influence outcome. Brief and time-limited treatments (e.g. $<10$ hours) are less likely to show benefits with clinical populations. More dramatic and durable effects have been achieved with protracted or time-unlimited programs extending up to 50 or 60 hours of treatment (see Kazdin, 1985). Second, specific training components, such as providing parents with in-depth knowledge of social learning principles and including time out from reinforcement in the behavior-change program (in addition to reinforcement) in the home, enhance treatment effects. Third, some evidence suggests that therapist training and skill are associated with the magnitude and durability of therapeutic changes, although this has yet to be carefully tested. Fourth, families characterized by many risk factors associated with childhood dysfunction (e.g. socioeconomic disadvantage, marital discord, parent psychopathology, poor social support) tend to show fewer gains in treatment than families without these characteristics and to maintain the gains less well (e.g. Dadds \& McHugh, 1992; Dumas \& Wahler, 1983; Webster-Stratton, 1985). Some efforts to address parent and family dysfunction during PMT have led to improved effects of treatment outcome for the child in some studies (e.g. Dadds, Schwartz \& Sanders, 1987; Griest et al., 1982) but not in others (Webster-Stratton, 1994). Much more work is needed on the matter, given the prominent role of parent and family dysfunction among many youths referred for treatment.

One promising line of work has focused on implementation of PMT in community, rather than clinic, settings. The net effect is to bring treatment to those persons least likely to come to or remain in treatment. In one study, for example, when PMT was delivered in small parent groups in the community, the effectiveness surpassed what was achieved with clinic-based PMT and was considerably more cost effective (Cunningham, Bremner \& Boyle, 1995).

Conceptual development of processes underlying parent-child interaction and conduct disorder continues (e.g. Patterson et al., 1992). Also, recent research on processes in treatment represents a related and important advance. A series of studies on therapist-parent interaction within PMT sessions has identified factors that contribute to parent resistance (e.g. parent saying, "I can't," "I won't"). The significance of this work is in showing that parent reactions in therapy relate to their discipline practices at home, that changes in resistance during therapy predicts change in parent behavior and that specific therapist ploys (e.g. reframing, confronting) can help overcome or contribute to resistance (Patterson $\&$ Chamberlain, 1994). This line of work advances our understanding of PMT greatly by relating in-session interactions of the therapist and parent to child functioning and treatment outcome.

Overall evaluation. Perhaps the most important point to underscore is that no other technique for conduct disorder has probably been studied as often or as well in controlled trials as has PMT. The outcome evidence makes PMT one of the most promising treatments. The evidence is bolstered by related lines of work. First, the study of family interaction processes that contribute to antisocial behavior in the home and evidence that changing these processes alters child behavior provide a strong empirical base for treatment. Second, the procedures and practices that are used in PMT (e.g. various forms of reinforcement and punishment practices) have been widely and effectively applied outside the context of conduct disorder. For example, the procedures have been applied with parents of children with autism, language delays, developmental disabilities, medical disorders for which compliance with special treatment regimens is required and with parents who physically abuse or neglect their children (see Kazdin, 1994b). Third, a great deal is known about the procedures and the parameters that influence the reinforcement and punishment practices that form the core of PMT. Consequently, very concrete recommendations can be provided to change behavior and to alter programs when behavior change has not occurred.

A major advantage is the availability of treatment manuals and training materials for parents and professional therapists (e.g. Forehand \& McMahon, 1981; Sanders \& Dadds, 1993). Also noteworthy is the development of self-administered videotapes of treatment. In a programmatic series of studies with young conduct problem children (3-8 years), Webster-Stratton and her colleagues have developed and evaluated videotaped materials to present PMT to parents; treatment can be self-administered in individual or group format supplemented with discussion (e.g. Webster-Stratton, 1994; Webster-Stratton, Hollinsworth \& Kolpacoff, 1989). Controlled studies have shown clinically significant changes at post-treatment and follow-up assessments with variations of videotaped treatment. The potential 
for extension of PMT with readily available and empirically tested videotapes presents a unique feature in child treatment.

Several limitations of PMT can be identified as well. First, some families may not respond to treatment. PMT makes several demands on the parents, such as mastering educational materials that convey major principles underlying the program, systematically observing deviant child behavior and implementing specific procedures at home, attending weekly sessions and responding to frequent telephone contacts made by the therapist. For some families, the demands may be too great to continue in treatment. Interestingly, within the approach several procedures (e.g. shaping parent behavior through reinforcement) provide guidelines for developing parent compliance and the desired response repertoire in relation to their children.

Second, perhaps the greatest limitation or obstacle in using PMT is that there are few training opportunities for professionals to learn the approach. Training programs in child psychiatry, clinical psychology, and social work are unlikely to provide exposure to the technique, much less opportunities for formal training. PMT requires mastery of social learning principles and multiple procedures that derive from them (Cooper, Heron \& Heward, 1987; Kazdin, 1994a). For example, the administration of reinforcement by the parent in the home (to alter child behavior) and by the therapist in the session (to change parent behavior) requires more than passing familiarity with the principle and the parametric variations that dictate its effectiveness (e.g. need to administer reinforcement contingently, immediately, frequently, to use varied and high quality reinforcers; prompting, shaping). The requisite skills in administering these within the treatment sessions can be readily trained but they are not trivial.

PMT has been applied primarily to parents of preadolescents. Although treatment has been effective with delinquent adolescents (Bank, Marlowe, Reid, Patterson $\&$ Weinrott, 1991) and younger adolescents with conduct problems who have not yet been referred for treatment (Dishion \& Andrews, 1995), some evidence suggests that treatment is more effective with preadolescent youths (see Dishion \& Patterson, 1992). Parents of adolescents may less readily change their discipline practices and also have higher rates of dropping out of treatment. The importance and special role of peers in adolescence and greater time that adolescents spend outside the home suggest that the principles and procedures may need to be applied in novel ways. At this point, few PMT programs have been developed specifically for adolescents, and so conclusions about the effects for youths of different ages must be tempered. On balance, PMT is one of the most promising treatment modalities. No other intervention for conduct disorder has been investigated as thoroughly as PMT.

\section{Functional Family Therapy}

Background and underlying rationale. Functional family therapy (FFT) reflects an integrative approach to treatment that has relied on systems, behavioral and cognitive views of dysfunction (Alexander, Holtzworth-
Munroe \& Jameson, 1994; Alexander \& Parsons, 1982). Clinical problems are conceptualized from the standpoint of the functions they serve in the family as a system, as well as for individual family members. The assumption is made that problem behavior evident in the child is the only way some interpersonal functions (e.g. intimacy, distancing, support) can be met among family members. Maladaptive processes within the family are considered to preclude a more direct means of fulfilling these functions. The goal of treatment is to alter interaction and communication patterns in such a way as to foster more adaptive functioning. Treatment is also based on learning theory and focuses on specific stimuli and responses that can be used to produce change. Sociallearning concepts and procedures, such as identifying specific behaviors for change and reinforcing new adaptive ways of responding, and empirically evaluating and monitoring change, are included in this perspective. Cognitive processes refer to the attributions, attitudes, assumptions, expectations and emotions of the family. Family members may begin treatment with attributions that focus on blaming others or themselves. New perspectives may be needed to help serve as the basis for developing new ways of behaving.

The underlying rationale emphasizes a family systems approach. Specific treatment strategies draw on findings that underlie PMT in relation to maladaptive and coercive parent-child interactions, discussed previously. FFT views interaction patterns from a broader systems view that also focuses on communication patterns and their meaning. As an illustration of salient constructs, research underlying FFT has found that families of delinquents show higher rates of defensiveness in their communications, both in parent-child and parent-parent interactions, blaming and negative attributions, and also lower rates of mutual support compared to families of nondelinquents (see Alexander \& Parsons, 1982). Improving these communication and support functions is a goal of treatment.

Characteristics of treatment. FFT requires that the family see the clinical problem from the relational function it serves within the family. The therapist points out interdependencies and contingencies between family members in their day-to-day functioning and with specific reference to the problem that has served as the basis for seeking treatment. Once the family sees alternative ways of viewing the problem, the incentive for interacting more constructively is increased.

The main goals of treatment are to increase reciprocity and positive reinforcement among family members, to establish clear communication, to help specify behaviors that family members desire from each other, to negotiate constructively and to help identify solutions to interpersonal problems. In therapy, family members identify behaviors they would like others to perform. Responses are incorporated into a reinforcement system in the home to promote adaptive behavior in exchange for privileges. However, the primary focus is within the treatment sessions, where family communication patterns are altered directly. During the sessions, the therapist provides social reinforcement (verbal and nonverbal praise) for communications that suggest solutions to problems, clarify problems or offer feedback. 
Overview of the evidence. Relatively few outcome studies have evaluated FFT (see Alexander et al., 1994). However, the available studies have focused on difficult to treat populations (e.g. adjudicated delinquent adolescents, multiple offender delinquents) and have produced relatively clear effects. In controlled studies, FFT has led to greater change than other treatment techniques (e.g. client-centered family groups, psychodynamically oriented family therapy) and various control conditions (e.g. group discussion and expression of feeling, no-treatment control groups). Treatment outcome is reflected in improved family communication and interactions and lower rates of referral to and contact of youth with the courts. Moreover, gains have been evident in separate studies up to $2 \frac{1}{2}$ years after treatment.

Research has examined processes in therapy to identify in-session behaviors of the therapist and how these influence responsiveness among family members (Alexander, Barton, Schiavo \& Parsons, 1976; Newberry, Alexander \& Turner, 1991). For example, providing support and structure and reframing (recasting the attributions and bases of a problem) can influence family member responsiveness and blaming of others. The relations among such variables are complex insofar as the impact of various type of statements (e.g. supportive) can vary as a function of gender of the therapist and family member. Evidence of change in processes proposed to be critical to FFT (e.g. improved communication in treatment, more spontaneous discussion) supports the conceptual view of treatment.

Overall evaluation. Several noteworthy points can be made about FFT. First, the outcome studies indicate that FFT can alter conduct problems among delinquent youth. Several studies have produced consistent effects. Second, the evaluation of processes that contribute to family member responsiveness within the sessions as well as to outcome represents a line of work rarely seen among treatment techniques for children and adolescents. Some of this process work has extended to laboratory (analog) studies to examine more precisely how specific types of therapist statements (e.g. reframing) can reduce blaming among group members (e.g. Morris, Alexander \& Turner, 1991). Third, a treatment manual has been provided (Alexander \& Parsons, 1982) to facilitate further evaluation and extension of treatment. Further work extending FFT to children and to clinic populations would be of interest in addition to the current work with delinquent adolescents. Also, further work on child, parent and family characteristics that moderate outcome would be a next logical step in the existing research program.

\section{Multisystemic Therapy}

Background and underlying rationale. Multisystemic therapy (MST) is a family-systems based approach to treatment (Henggeler \& Borduin, 1990). Family approaches maintain that clinical problems of the child emerge within the context of the family and focus on treatment at that level. MST expands on that view by considering the family as one, albeit a very important, system. The child is embedded in a number of systems including the family (immediate and extended family members), peers, schools, neighborhood and so on. For example, within the context of the family, some tacit alliance between one parent and the child may contribute to disagreement and conflict over discipline in relation to the child. Treatment may be required to address the alliance and sources of conflict in an effort to alter child behavior. Also, child functioning at school may involve limited and poor peer relations; treatment may address these areas as well. Finally, the systems approach entails a focus on the individual's own behavior insofar as it affects others. Individual treatment of the child or parents may be included in treatment.

Because multiple influences are entailed by the focus of the treatment, many different treatment techniques are used. Thus, MST can be viewed as a package of interventions that are deployed with children and their families. Treatment procedures are used on an "as needed" basis directed toward addressing individual, family and system issues that may contribute to problem behavior. The conceptual view, focusing on multiple systems and their impact on the individual, serves as a basis for selecting multiple and quite different treatment procedures.

Characteristics of treatment. Central to MST is a family-based treatment approach. Several family therapy techniques (e.g. joining, reframing, enactment, paradox and assigning specific tasks) are used to identify problems, increase communication, build cohesion, and alter how family members interact. The goals of treatment are to help the parents develop behaviors of the adolescent, to overcome marital difficulties that impede the parents' ability to function as parents, to eliminate negative interactions between parent and adolescent and to develop or build cohesion and emotional warmth among family members.

MST draws on many other techniques as needed to address problems at the level of individual, family and extrafamily. As prominent examples, PSST, PMT, and marital therapy are used in treatment to alter the response repertoire of the adolescent, parent-child interactions at home and marital communication, respectively. In some cases, treatment consists of helping the parents address a significant domain through practical advice and guidance (e.g. involving the adolescent in prosocial peer activities at school, restricting specific activities with a deviant peer group). Although MST includes distinct techniques of other approaches, it is not a mere amalgamation of them. The focus of treatment is on interrelated systems and how they affect each other. Domains may be addressed in treatment (e.g. parent unemployment) because they raise issues for one or more systems (e.g. parent stress, increase in alcohol consumption) and affect how the child is functioning (e.g. marital conflict, child discipline practices).

Overview of the evidence. Several outcome studies have evaluated MST, primarily with delinquent youths with arrest and incarceration histories including violent crime (e.g. manslaughter, aggravated assault with intent to kill). Thus, this is a group of extremely antisocial and aggressive youth. Results have shown MST to be superior in reducing delinquency, emotional and behavioral problems and in improving family functioning in comparison to other procedures including "usual services" provided to such youths (e.g. probation, court-ordered activities 
that are monitored such as school attendance), individual counseling and community-based eclectic treatment (e.g. Borduin et al., 1995; Henggeler et al., 1986; Henggeler, Melton, \& Smith, 1992). Follow-up studies up to 2, 4 and 5 years later with separate samples have shown that MST youths have lower arrest rates than youths who receive other services (see Henggeler, 1994).

Research has also shown that treatment affects critical processes proposed to contribute to deviant behavior (Mann, Borduin, Henggeler, \& Blaske, 1990). Specifically, parents and teenage youths show a reduction in coalitions (e.g. less verbal activity, conflict and hostility) and increases in support, and the parents show increases in verbal communication and decreases in conflict. Moreover, decreases in adolescent symptoms are positively correlated with increases in supportiveness and decreases in conflict between the mother and father. This work provides an important link between theoretical underpinnings of treatment and outcome effects.

Overall evaluation. Several outcome studies are available for MST and they are consistent in showing that treatment leads to change in adolescents and that the changes are sustained. A strength of the studies is that many of the youths who are treated are severely impaired (delinquent adolescents with a history of arrest). Another strength is the conceptualization of conduct problems at multiple levels, namely, as dysfunction in relation to the individual, family and extrafamilial systems and the transactions among these. In fact, youths with conduct disorder experience dysfunction at multiple levels including individual repertoires, family interactions and extrafamilial systems (e.g. peers, schools, employment among later adolescents). MST begins with the view that may different domains are likely to be relevant; they need to be evaluated and then addressed as needed in treatment.

A challenge of the approach is deciding what treatments to use in a given case, among the many interventions encompassed by MST. Guidelines are available to direct the therapist, although they are somewhat general (e.g. focus on developing positive sequences of behaviors between systems such as parent and adolescent, evaluate the interventions during treatment so that changes can be made; see Henggeler, 1994). Providing interventions as needed is very difficult without a consistent way to assess what is needed, given inherent limits of decision making and perception, even among trained professionals. Related to this, the administration of MST is demanding in light of the need to provide several different interventions in a high-quality fashion. Individual treatments (e.g. PSST, PMT) alone are difficult to provide; multiple combinations invite problems related to providing treatments of high quality, strength and integrity. Yet there have been replications of MST beyond the original research program, indicating that treatment can be extended across therapists and settings (Henggeler, Schoenwald \& Pickrel, 1995).

On balance, MST is quite promising given the quality of evidence and consistency in the effects that have been produced. The promise stems from a conceptual approach that examines multiple domains (systems) and their contribution to dysfunction, evidence on processes in therapy and their relation to outcome and the outcome studies themselves. The outcome studies have extended to youths with different types of problems (e.g. sexual offenses, drug use) and to parents who engage in physical abuse or neglect (e.g. Borduin, Henggeler, Blaske \& Stein, 1990; Brunk, Henggeler \& Whelan, 1987). Thus, the model of providing treatment may have broad applicability across problem domains among seriously disturbed children. In passing, it may be worth noting that other literatures are relevant to MST. Some of the techniques included in treatment are variations of PSST and PMT, already discussed, and hence have evidence on their own behalf as effective interventions.

\section{Limitations of Promising Treatments}

Each of the treatments just discussed has randomized, controlled trials on its behalf, includes replications of treatment effects in multiple studies, focuses on youths whose aggressive and antisocial behavior have led to impairment and referral to social services (e.g. clinics, hospitals, courts) and has assessed outcome over the course of follow-up, at least up to a year, but often longer. Even though these treatments have made remarkable gains, they also bear limitations worth highlighting.

Magnitude of therapeutic change. Promising treatments have achieved change, but is the change enough to make a difference in the lives of the youths who are treated? Clinical significance refers to the practical value or importance of the effect of an intervention, that is, whether it makes any "real" difference to the patients or to others with whom they interact (see Kazdin, 1992). Clinical significance is important because it is quite possible for treatment effects to be statistically significant, but not to have impact on most or any of the cases in a way that improves their functioning or adjustment in daily life.

There are several ways to evaluate clinical significance. As an example, one way is to consider the extent to which youths function at normative levels at the end of treatment (i.e. compared to same age and sex peers who are functioning well). This is particularly useful as a criterion in relation to children and adolescents because base rates of emotional and behavioral problems can vary greatly as a function of age. Promising treatments occasionally have shown that treatment returns individuals to normative levels in relation to behavioral problems and prosocial functioning at home and at school (see Kazdin, 1995b). Yet, the majority of studies, whether of promising or less well-evaluated treatments, have not examined whether youths have changed in ways that place them within normative range of functioning or have made gains that would reflect clinically significant changes (Kazdin, Bass, Ayers \& Rodgers, 1990a).

Although the goal of treatment is to effect clinically significant change, other less dramatic goals are not trivial. For many conduct-disordered youths, symptoms may escalate, comorbid diagnoses (e.g. substance abuse, depression) may emerge and family dysfunction may increase. Also, such youths are at risk for teen marriage, dropping out of school and running away. If treatment were to achieve stability in symptoms and family life and prevent or delimit future dysfunction, that would be a significant achievement. The reason evaluation is so 
critical to the therapeutic enterprise is to identify whether treatment makes a difference because "making a difference" can have many meanings that are important in the treatment of conduct disorder.

Maintenance of change. Promising treatments have included follow-up assessment, usually up to a year after treatment. Yet, conduct disorder has a poor long-term prognosis, so it is especially important to identify whether treatment has enduring effects. Also, in evaluating the relative merit of different treatments, follow-up data play a critical role. When two (or more) treatments are compared, the treatment that is more (or most) effective immediately after treatment is not always the one that proves to be the most effective treatment in the long run (Kazdin, 1988). Consequently, the conclusions about treatment may be very different depending on the timing of outcome assessment. Apart from conclusions about treatment, follow-up may provide important information that permits differentiation among youths. Over time, youths who maintain the benefits of treatment may differ in important ways from those who do not. Understanding who responds and who responds more or less well to a particular treatment can be very helpful in understanding, treating and preventing conduct disorder.

The study of long-term effects of treatment is difficult in general, but the usual problems are exacerbated by focusing on conduct disorder. Among clinic samples, families of conduct-disordered youths have high rates of dropping out during treatment and during the follow-up assessment period, due in part to the many parent and family factors (e.g. socioeconomic disadvantage, stress) often associated with the problem (Kazdin, 1996b). As the sample size decreases over time, conclusions about the impact of treatment become increasingly difficult to draw. Nevertheless, evaluation of the long-term effects of treatment remains a high priority for research.

Limited assessment of outcome domains. In the majority of child therapy studies, child symptoms are the exclusive focus of outcome assessment (Kazdin et al., 1990a). Other domains such as prosocial behavior and academic functioning are neglected, even though they relate to concurrent and long-term adjustment (e.g. Asher \& Coie, 1990). Perhaps the greatest single deficit in the evaluation of treatment is absence of attention to impairment. Impairment reflects the extent to which the individual's functioning in everyday life is impeded. Impairment can be distinguished from symptoms insofar as individuals with similar levels of symptoms (e.g. scores), diagnoses and patterns of comorbidity are likely to be distinguishable based on their ability to function adaptively. School and academic functioning, peer relations, participation in activities and health are some of the areas included in impairment. In the context of treatment, an intervention may significantly reduce symptoms. Yet, is there any change or reduction in impairment? The impact of treatment on impairment is arguably as important as the impact on the conduct disorder symptoms.

Beyond child functioning, parent and family functioning may also be relevant. Parents and family members of conduct-disordered youths often experience dysfunction (e.g. psychiatric impairment, marital conflict). Also, the problem behaviors of the child are often part of complex, dynamic and reciprocal influences that affect all relations in the home. Consequently, parent and family functioning and the quality of life for family members are relevant outcomes and may be appropriate goals for treatment.

In general, there are many outcomes that are of interest in evaluating treatment. From existing research we already know that the conclusions reached about a given treatment can vary depending on the outcome criterion. Within a given study, one set of measures (e.g. child functioning) may show no differences between two treatments but another measure (e.g. family functioning) may show that one treatment is clearly better than the other (e.g. Kazdin, Bass, Siegel \& Thomas, 1989; Kazdin, Siegel \& Bass, 1992; Szapocznik et al., 1989). Thus, in examining different outcomes of interest, we must be prepared for different conclusions that these outcomes may yield.

\section{General Comments}

In light of these comments, clearly even the most promising treatments have several limitations. Yet it is critical to place these in perspective. The most commonly used treatments in clinical practice consist of "traditional " approaches including psychodynamic, relationship, play and family therapies (other than those mentioned earlier) (Kazdin, Siegel \& Bass, 1990b). These treatments have rarely been tested in controlled outcome studies showing that they achieve therapeutic change in referred (or nonreferred) samples of youth with conduct problems. Many forms of behavior therapy have a rather extensive literature showing that various techniques (e.g. reinforcement programs, social skills training) can alter aggressive and other antisocial behaviors (Kazdin, 1985; McMahon \& Wells, 1989). Yet the focus has tended to be on isolated behaviors, rather than a constellation of symptoms. Also, durable changes among clinical samples have rarely been shown.

Pharmacotherapy represents a line of work of some interest. For one reason, stimulant medication (e.g. methylphenidate), frequently used with children diagnosed with ADHD, has some impact on aggressive and other antisocial behaviors (see Hinshaw, 1994). This is interesting in part because such children often have a comorbid diagnosis of Conduct Disorder. Still no strong evidence exists that stimulant medication can alter the constellation of symptoms (e.g. fighting, stealing) associated with conduct disorder. A review of various medications for aggression in children and adolescents has raised possible leads, but the bulk of research consists of uncontrolled studies (see Campbell \& Cueva, 1995; Stewart, Myers, Burket \& Lyles, 1990). Controlled studies (e.g. random assignment, placebo-controls) have shown antiaggressive effects with some medications (e.g. lithium; Campbell et al., 1995) but not others (e.g. carbamazepine; Cueva et al., 1996). Reliable psychopharmacological treatments for aggression, leaving aside the constellation of conduct disorder (e.g. firesetting, stealing, and so on), remain to be developed.

There is a genre of interventions that are worth mentioning but are even less well evaluated than many of the psychotherapies and pharmacotherapies. Occasionally, interventions are advocated and implemented, 
such as sending conduct-disordered youths to a camp in the country where they learn how to "rough it," or how to take care of horses or to experience military (e.g. basic training) regimens. The conceptual bases of such treatments, research identifying processes involved in the onset of conduct disorders and related criteria (noted earlier in the paper) are rarely even approximated with this genre of interventions. Typically, such programs are not evaluated empirically. On the one hand, developing treatments that emerge outside of the mainstream of the mental health professions is to be encouraged precisely because traditional treatments have not resolved the problem. On the other hand, this genre of intervention tends to avoid evaluation. Evaluation is the key because well-intentioned and costly interventions can have little or no effect on the youths they treat (Weisz, Walter, Weiss, Fernandez \& Mikow, 1990) and may actually increase antisocial behavior (e.g. see Lundman, 1984).

\section{Salient Clinical Issues in Treatment}

There are a number of issues that emerge in treatment of conduct-disordered youths and decision-making about what interventions to provide to whom. These issues reflect obstacles in delivering treatment, lacunae in our knowledge base and limitations in the models of providing care.

\section{Retaining Cases in Treatment}

Dropping out from treatment is a significant problem in the treatment of children and adolescents. ${ }^{3}$ Among families that begin treatment, 40-60\% terminate prematurely (Armbruster \& Kazdin, 1994; Wierzbicki \& Pekarik, 1993). Youths with aggressive and antisocial behavior are particularly likely to drop out early (e.g. Capaldi \& Patterson, 1987; Kaminer, Tarter, Bukstein \& Kabene, 1992).

Many of the parent and family factors often associated with conduct disorder are likely to place families at risk for terminating treatment prematurely. These include: socioeconomic disadvantage, facets of the family constellation (younger mothers, single-parent families), high parent stress, adverse child-rearing practices (e.g. harsh punishment, poor monitoring and supervision of the child) and parent history of antisocial behavior (e.g. Kazdin, 1990; Kazdin, Mazurick \& Bass, 1993; McMahon, Forehand, Griest \& Wells, 1981). Child characteristics that predict early termination from treatment include comorbidity (multiple diagnoses and symptoms across a range of disorders), severity of delinquent and antisocial behavior and poor academic functioning. The accumulation of these factors places families at

\footnotetext{
${ }^{3}$ Dropping out of treatment usually refers to prematurely terminating from ongoing therapy at a point where the patient ceases to come for treatment and when the therapist believes that this decision is ill-advised. In research, early termination usually refers to dropping out within the first few sessions of treatment, although the patient may leave the system at many different points (e.g. after being referred to the clinic, contacting the clinic by phone, scheduling an initial appointment, attending that appointment, beginning intake assessment).
}

increased risk for dropping out of treatment within the first few sessions. Interestingly, many of the child, parent and family factors that predict premature termination from treatment are the same factors that portend a poor response to treatment and poor long-term prognosis (Dadds \& McHugh, 1992; Dumas \& Wahler, 1983; Kazdin, 1995a; Webster-Stratton, 1985).

The cases who terminate early are those who evince the greatest impairment in parent, family and child characteristics. In clinical work, the usual impression is that individuals who drop out of treatment are much worse off than those who have remained in treatment. Our own work suggests that this is true, but due primarily to the fact that those who drop out are more severely impaired to begin with (Kazdin, Mazurick \& Siegel, 1994). Even so, evidence points to benefits of remaining in treatment. Those cases who remain in treatment but are equally impaired as those who have dropped out tend to fare better. Consequently, it is important to retain cases in treatment.

Even though treatment is designed to help families, several aspects of coming to treatment increase stress and demands on the family. Many of the burdens are associated with coming to the sessions and include procuring transportation, cajoling the identified patient (child) to agree to come to the session that day, arranging babysitting for other children and so on. In fact, parents will often cancel a session or not show up because of the difficulties of bringing the child and the child's siblings to the clinic. Financial costs associated with coming to treatment (e.g. babysitting, transportation, costs of treatment) also may be a significant burden in light of the disproportionate distribution of poverty among families of youths referred to treatment for conduct disorder.

There are a few leads for retaining cases better in treatment, although the empirical evidence in relation to child and adolescent treatment is sparse. Providing special sessions for the parents to address sources of stress and concern (e.g. job stress, personal worries, family disputes), when added to treatment of the child, reduces attrition (Prinz \& Miller, 1994). Also, providing children with a special preparatory interview to convey why people go to therapy reduces the rate of dropping out (Holmes \& Urie, 1975). Developing an alliance with all immediate family members (e.g. by extensive phone contacts) early in treatment, conveying the benefits that can accrue to each member as the child improves and making an effort to engage the family members in treatment as obstacles emerge have reduced attrition and improved treatment outcome (Santisteban et al., 1996; Szapocznik et al., 1988).

Clinically, adding interventions just to retain cases in treatment can place a burden on the therapy. Yet cases at high risk for dropping out can be identified, based on factors mentioned previously. In these cases, it may be feasible for the clinician to attack both fronts, namely, improvement of the conduct-disordered child and reduction of parental stress and the burden of treatment. It is unlikely that improvements in child functioning alone will help retain cases in treatment, given what we know about the factors that predict treatment termination. In fact, in our own clinical work, early improvement in treatment seems to increase the likelihood of attrition. 
Some parents perceive early changes as sufficient, even though many areas may require further attention.

\section{What Treatments Do Not Work}

With a few hundred or so treatments available for children, it would be quite helpful to know which among these do not work or do not work very well. Addressing the matter directly is not possible in light of the fact, noted previously, that the vast majority of treatment approaches have not been evaluated empirically. Thus, there is no accumulated body of evidence in which treatments have consistently emerged as weak or ineffective. Moreover, the nature of the dominant scientific research paradigm (inability to prove the null hypothesis) precludes firm demonstration of no effects of treatment. Most of the treatments currently used in clinical work (Kazdin et al., 1990b), including psychodynamic therapy, relationship-based treatment and play therapy, have not been evaluated empirically (Kazdin et al., 1990a). Occasionally, variations of these treatments have been used as comparative conditions and have been shown to be less effective than one of the promising treatments noted previously (e.g. Borduin et al., 1995; Kazdin, EsveldtDawson, French \& Unis, 1987a, b). From this limited research, it is premature to conclude that these latter treatments are ineffective. Yet at best their benefits have still to be demonstrated and more promising treatments with firmer empirical bases are currently the treatments of choice.

The absence of empirical evidence is only one criterion, albeit an obviously important one. In advance of, and eventually along with, the evidence, scrutiny of the conceptual underpinnings of treatment and the treatment focus is important in relation to what we know about conduct disorder. We know, for example, that conductdisordered youths usually show problems in multiple domains, including overt behavior, social relations (e.g. peers, teachers, family members) and academic performance. For a treatment to be effective, it is likely that several domains have to be addressed explicitly within the sessions or a conceptual model (with supporting evidence) is needed to convey why a narrow or delimited focus (e.g. on psychic conflicts or a small set of overt behaviors) is likely to have broad effects on domains not explicitly addressed in treatment. Although one cannot say for certain what techniques will not work, it is much safer to say that treatments that neglect multiple domains are likely to have limited effects.

Second, some evidence has emerged that is useful for selecting what treatments to avoid or to use with great caution. Often conduct-disordered youths are treated in group therapy, yet placing youths together could impede improvement. For example, Feldman, Caplinger and Wodarski (1983) randomly assigned youths (ages 8-17) to variations of group therapy. In one type of group, all members were referred for conduct disorder; in another type of group, conduct-disordered youths were placed with nonantisocial youths (without clinical problems). Those placed in a group of their deviant peers did not improve; those placed with nondeviant peers did improve. Interpretation of this is based on the likelihood that peer bonding to others can improve one's behavior, if those peers engage in more normative behavior; bonding to a deviant group can sustain deviant behavior.

Similarly, Dishion and Andrews (1995) evaluated several interventions for nonreferred youths (ages 10-14) with conduct problems. One of the treatment conditions included youths meeting in a group with a focus on selfregulation, monitoring and developing behavior-change programs. This condition, whether alone or in combination with parent training, was associated with increases in behavioral problems and substance use (cigarette smoking). Again, it appeared that placing conductproblem teens in a group situation can exacerbate their problems. Other research has shown that individuals may become worse (e.g. increase in arrest rates) through association with deviant peers as part of treatment (O'Donnell, 1992).

Treatments for conduct-disordered youths in settings such as hospitals, schools and correctional facilities are often conducted in a group therapy format in which several conduct-problem youths are together to talk about or work on their problems or go to the country for some fresh air experience to get better. There may be conditions under which this arrangement is beneficial. However, current research suggests that placing several such youths together can impede therapeutic change and have deleterious effects.

\section{Who Responds Well to Treatment}

We have known for many years that the critical question of psychotherapy is not what technique is effective, but rather what technique works for whom, under what conditions, as administered by what type of therapists, and so on (Kiesler, 1971). The adult psychotherapy literature has focused on a range of questions to identify factors (e.g. patient, therapist, treatment process) that contribute to outcome. The child and adolescent therapy research has been devoted almost exclusively to questions about treatment technique, with scant attention to the role of child, parent, family and therapist factors that may moderate outcome (Kazdin et al., 1990a).

In the case of conduct disorder, a few studies have looked at who responds to treatment, mostly in the context of parent management training and problemsolving skills training. Current evidence suggests that risk factors for onset of conduct disorder and poor long-term prognosis also predict response to treatment (Dumas \& Wahler, 1983; Kazdin, 1995a, Kazdin \& Crowley, in press; Webster-Stratton, 1985). Multiple child, parent, family and contextual factors, including early onset and more severe child antisocial behavior, comorbid diagnoses, child academic impairment, socioeconomic disadvantage, single-parent families, parental stress (perceived) and life events, and parent history of antisocial behavior in childhood are likely to influence responsiveness to treatment. These factors accumulate and increase risk for poor outcome in treatment. Our own work has shown that even those youths with multiple risk factors still improve with treatment, but the changes are not as great as those achieved for cases with fewer risk factors. The characteristics that have been studied in 
relation to treatment outcome (e.g. comorbidity) have not been examined across different treatments. Consequently, we do not know whether these factors affect responsiveness to any treatment or to particular forms of treatment.

In current subtyping of conduct-disordered youths, early (childhood) and later (adolescent) onset conduct disorder are distinguished (Hinshaw et al., 1993; Moffitt, 1993). Early-onset conduct-disordered youths are characterized by aggressive behavior, neuropsychological dysfunction (in "executive" functions), a much higher ratio of boys to girls and a poor long-term prognosis. Lateronset youths (onset at about age 15) are characterized more by delinquent activity (theft, vandalism), a more even distribution of boys and girls and a more favorable prognosis. The subtype and associated characteristics are by no means firmly established, but reflect current conceptual and empirical work in the area (e.g. Moffitt, 1993; Patterson, DeBaryshe \& Ramsey, 1989). We can expect from this that youths with an early onset are more likely to be recalcitrant to treatment. At present, and in the absence of very much treatment research on the matter, a useful guideline to predict responsiveness to treatment is to consider loading of the child, parent and family on risk factors that portend a poor long-term prognosis (see Kazdin, 1995b; Robins, 1991).

In clinical work, there is frequent discussion about the importance of individualizing treatment to the needs of the child and family. At this point, the research is of little help in addressing the level of specificity in crafting treatment regiments to the individual. A possible exception is one of the treatments mentioned previously (multisystemic therapy), in which several different treatments, some with firm evidence on their behalf, are integrated as a treatment package. At present, perhaps the best strategy is to select the treatment that appears to be promising based on the evidence and applying that as the initial treatment of choice. Attempting to make decisions about what can be applied effectively among promising or unpromising techniques is difficult to do in an informed way in light of the current knowledge base and could very well lead to less effective clinical care for the individual child and family.

\section{Addressing Comorbidity}

An issue that has received attention in discussions of clinical dysfunction and treatment is the issue of comorbidity. As noted previously, conduct disorder is often comorbid with other diagnoses, most notably ADHD and ODD, but others as well. It is likely that comorbidity is the rule rather than the exception among cases referred for treatment. In our own clinic, for example, approximately $70 \%$ of the cases meet DSM criteria for two or more disorders (Kazdin, 1996b).

Comorbidity has been conceived of rather narrowly, namely, the presence of two or more disorders. In relation to treatment research and practice, there may be value in extending the notion more broadly. It is likely that children have many symptoms from many different disorders, even though they might not meet the criteria for each of the disorders. Indeed, in our research we have found the total number of symptoms across the range of disorders to be a more sensitive predictor of treatment outcome than merely counting the number of diagnoses (Kazdin \& Crowley, in press). Although the number of disorders may be important, impairment across the full range of symptoms is noteworthy as well.

It may be useful to expand the notion of comorbidity well beyond symptoms and diagnoses. A central issue for treating conduct-disordered youth is the domains of impairment they experience. These domains can include other disorders (e.g. depression, substance abuse), learning difficulties (specific reading disorders, language delays, learning disability), dysfunctional peer relations (rejection, absence of prosocial friends) and perhaps deficits in prosocial activities (participation in school, athletic and extracurricular events). Problems or dysfunctions in each of these domains, apart from conductdisorder symptoms themselves, can influence the effects of treatment and long-term prognosis.

At present, research has not provided guidelines for how to address comorbid conditions. Indeed, much of the treatment research has eschewed diagnosis, so the number or proportions of youth who meet criteria for any disorder is usually unclear (Kazdin et al., 1990a). We can say very little at this point about whether comorbid conditions invariably influence outcome, whether the influence and direction of that influence vary by the specific comorbid condition, or how to alter treatment in light of these conditions. This area of work represents a major deficiency in the knowledge base among even the most promising treatments for conduct disorder.

\section{Combining Treatments}

There is keen interest, both in clinical work and in research, in using combinations of treatment, i.e. multiple psychosocial and/or pharmacological interventions (see Kazdin, 1996a). In the case of conduct disorder, impetus stems from the scope of impairment evident in children (e.g. comorbidity, academic dysfunction) and families (e.g. stress, conflict) as well as limited effects of most treatments. The benefits of combined treatments can be identified in selected areas. For example, in the treatment of adult schizophrenia, combinations of treatment (e.g. medication and family counseling/therapy) surpasses the effects of the constituent components alone (e.g. Falloon, 1988).

In the case of child and adolescent therapy, combined treatments have not been well studied. I have argued elsewhere that there are many reasons to expect combined treatments not to surpass the effects of any promising single treatment (Kazdin, 1996a). Among the reasons, we know very little about the parameters of a given treatment that influence its effectiveness and the cases to whom the treatment is most suitably applied. Combining techniques of which we know relatively little, particularly in timelimited treatment, is not a firm base to build more effective treatments: Also, there are many obstacles in combining treatment that materially affect their likely outcome, such as decision rules regarding what treatments to combine, how to combine them (e.g. when, in what order), how to evaluate their impact and others. 
An important assumption for combined treatments is that individual treatments are weak and, if combined, they would produce additive or synergistic effects. This is a reasonable, even if poorly tested, assumption. An alternative assumption is that the way in which treatment is usually administered, whether a single or a combined treatment, inherently limits the likelihood of positive outcome effects, a point discussed further later. As a general point, combining treatments itself is not likely to be an answer to developing effective treatment without more thought and evidence about the nature of these combinations.

Some of the promising treatments reviewed previously (MST, FFT) are combined treatments. For example, multisystemic therapy provides many different treatments for antisocial youths. Two points are worth noting. First, the constituent treatments that form a major part of treatment are those that have evidence on their behalf (e.g. PSST, PMT), so that not any combination is used. Second, we do not yet know that multisystemic therapy, as a combined treatment package, is more effective than the most effective constituent component administered for the same duration. The comparisons of multisystemic therapy have mostly included ordinary individual psychotherapy and counseling, important comparison groups to be sure. Although treatment has surpassed traditional therapy practices, this is not the same as showing that combinations of treatment per se are necessary to achieve therapeutic changes.

Combined treatments may be very useful and should be pursued. At the same time, a rash move to combine treatments is unwarranted. The effects of combined treatment obviously depend very much on the individual treatments that are included in the combination. For example, mentioned already was a study in which parent training and a teen-focused group were evaluated alone and in combination (Dishion \& Andrews, 1995). Conditions that received the teen-group component, whether alone or in combination with parent training, became worse. Obviously, one cannot assume that combined treatments will automatically be neutral or better than their constituent treatments. There is another more subtle and perhaps worrisome facet of combined treatments. A danger in promoting treatment combinations is to continue to use techniques with little evidence on their behalf as an ingredient in a larger set of techniques. Old wine in new bottles is not bad if the original wine has merit. However, without knowing if there is merit, the tendency to view the wine as new and improved would be unfortunate. With promising treatments available, we have a comparative base to evaluate novel treatments, treatment combinations, and unevaluated treatments in current use. If a promising treatment is not used in clinical work, we would want evidence that it has clearly failed, that other promising treatments for whatever reason cannot be used and that the treatment that is to be applied has a reasonable basis for addressing the scope of dysfunctions.

\section{Models of Delivering Treatment}

The model of treatment delivery in current research is to provide a relatively brief and time-limited intervention.
For several clinical dysfunctions or for a number of children with a particular dysfunction such as conduct disorder, the course of maladjustment may be long-term. In such cases, the notion of providing a brief, time-limited treatment may very much limit outcome effects. Even if a great combination of various psychotherapies were constructed, administration in the time-limited fashion might have the usual, checkered yield. More extended and enduring treatment in some form may be needed to achieve clinically important effects with the greatest number of youths. Two ways of delivering extended treatment illustrate the point.

The first variation might be referred to as a continuedcare model. The model of treatment delivery that may be needed can be likened to the model used in the treatment of diabetes mellitus. With diabetes, ongoing treatment (insulin) is needed to ensure that the benefits of treatment are sustained. The benefits of treatment would end with discontinuation of treatment. Analogously, in the context of conduct disorder, a variation of ongoing treatment may be needed. Perhaps after the child is referred, treatment is provided to address the current crises and to have impact on functioning at home, at school and in the community. After improvement is achieved, treatment is modified rather than terminated. At that point, the child could enter into maintenance therapy, i.e. continued treatment perhaps in varying schedules ("doses"). Treatment would continue but perhaps on a more intermittent basis. Continued treatment in this fashion has been effective as a model for treating recurrent depression in adults (see Kupfer et al., 1992).

The second variation might be referred to as a dentalcare model to convey a different way of extending treatment. After initial treatment and demonstrated improvement in functioning in everyday life, treatment is suspended. At this point, the child's functioning begins to be monitored regularly (e.g. every 3 months) and systematically (with standardized measures). Treatment could be provided pro re nata (PRN) based on the assessment data or emergent issues raised by the family, teachers or others. The approach might be likened to the more familiar model of dental care in the United States in which "check-ups" are recommended every 6 months; an intervention is provided if and as needed, based on these periodic checks.

Obviously, the use of ongoing treatment is not advocated in cases where there is evidence that short-term treatment is effective. A difficulty with most of the research on treatment of conduct disorder, whether promising, poorly investigated or combined treatments, is that the conventional treatment model of brief, timelimited therapy has been adopted. Without considering alternative models of delivery, current treatments may be quite limited in the effects they can produce. Although more effective treatments are sorely needed, the way of delivering currently available treatments ought to be reconsidered.

\section{Conclusions}

Many different types of treatment have been applied to conduct-disordered youths. Unfortunately, little outcome evidence exists for most of the techniques. Four 
treatments with the most promising evidence to date were highlighted: problem-solving skills training, parent management training, functional family therapy, and multisystemic therapy. Cognitive problem-solving skills training focuses on cognitive processes that underlie social behavior. Parent management training is directed at altering parent-child interactions in the home, particularly those interactions related to child-rearing practices and coercive interchanges. Functional family therapy utilizes principles of systems theory and behavior modification as the basis for altering interactions, communication and problem solving among family members. Multisystemic therapy focus on the individual, family and extrafamilial systems and their interrelations as a way to reduce symptoms and to promote prosocial behavior. Evidence on behalf of these interventions was reviewed; each has multiple controlled studies on its behalf and some of the techniques (e.g. PMT) have been extraordinarily well evaluated.

Significant issues remain to be addressed to accelerate advances in the area of treatment. The magnitude of change and durability of treatment effects raise multiple issues about how to evaluate treatment and the conclusions reached about any particular intervention. We cannot yet say that one intervention can ameliorate conduct disorder and overcome the poor long-term prognosis. On the other hand, much can be said. Much of what is practised in clinical settings is based on psychodynamically oriented treatment, general relationship counseling, family therapy and group therapy (with antisocial youths as members). These and other procedures, alone and in various combinations in which they are often used, have not been evaluated carefully in controlled trials. Of course, absence of evidence is not tantamount to ineffectiveness. At the same time, promising treatments have advanced considerably and a very special argument might be needed to administer treatments that have neither basic research on their conceptual underpinnings in relation to conduct disorder nor outcome evidence from controlled clinical trials on their behalf. Promising treatments, at best, leave important questions unanswered. Further development of treatments is clearly needed. Apart from treatment studies, further progress in understanding the nature of conduct disorder is likely to have very important implications for improving treatment outcome. Improved triage of patients to treatments that are likely to work will require understanding of characteristics of children, parents and families that will make them more or less amenable to current treatments.

Acknowledgements-Completion of this paper was supported by a Research Scientist Award (MH00353) and a grant (MH35408) from the National Institute of Mental Health. Support for this work is gratefully acknowledged.

\section{References}

Alexander, J. F., Barton, C., Schiavo, R. S. \& Parsons, B. V. (1976). Systems-behavioral intervention with families of delinquents: Therapist characteristics, family behavior, and outcome. Journal of Consulting and Clinical Psychology, 44, 656-664.
Alexander, J. F., Holtzworth-Munroe, A. \& Jameson, P. B. (1994). The process and outcome of marital and family therapy research: Review and evaluation. In A. E. Bergin \& S. L. Garfield (Eds.), Handbook of psychotherapy and behavior change (4th edn.), (pp. 595-630). New York: John Wiley \& Sons.

Alexander, J. F. \& Parsons, B. V. (1982). Functional family therapy. Monterey, CA: Brooks/Cole.

American Psychiatric Association (1994). Diagnostic and statistical manual of mental disorders (4th edn.). Washington, DC: APA.

Armbruster, P., \& Kazdin, A. E. (1994). Attrition in child psychotherapy. In T. H. Ollendick \& R. J. Prinz (Eds.), Advances in clinical child psychology, Vol. 16 (pp. 81-108). New York: Plenum.

Asher, S. R. \& Coie, J. D. (Eds.) (1990). Peer rejection in childhood. New York: Cambridge University Press.

Baer, R. A. \& Nietzel, M. T. (1991). Cognitive and behavioral treatment of impulsivity in children: A meta-analytic review of the outcome literature. Journal of Clinical Child Psychology, 20, 400-412.

Bank, L., Marlowe, J. H., Reid, J. B., Patterson, G. R. \& Weinrott, M. R. (1991). A comparative evaluation of parenttraining interventions for families of chronic delinquents. Journal of Abnormal Child Psychology, 19, 15-33.

Bell, R. Q. \& Harper, L. (1977). Child effects on adults. New York: John Wiley \& Sons.

Borduin, C. M., Henggeler, S. W., Blaske, D. M. \& Stein, R. (1990). Multisystemic treatment of adolescent sexual offenders. International Journal of Offender Therapy and Comparative Criminology, 34, 105-113.

Borduin, C. M., Mann, B. J., Cone, L. T., Henggeler, S. W., Fucci, B. R., Blaske, D. M. \& Williams, R. A. (1995). Multisystemic treatment of serious juvenile offenders: Longterm prevention of criminality and violence. Journal of Consulting and Clinical Psychology, 63, 569-578.

Brandt, D. E. \& Zlotnick, S. J. (1988). The psychology and treatment of the youthful offender. Springfield, IL: Charles C Thomas.

Brunk, M., Henggeler, S. W. \& Whelan, J. P. (1987). A comparison of multisystemic therapy and parent training in the brief treatment of child abuse and neglect. Journal of Consulting and Clinical Psychology, 55, 311-318.

Campbell, M., Adams, P. B., Small, A. M., Kafantaris, V., Silva, R. R., Shell, J., Perry, R. \& Overall, J. E. (1995). Lithium in hospitalized aggressive children with conduct disorder: A double-blind and placebo-controlled study. Journal of the American Academy of Child and Adolescent Psychiatry, 34, 445-453.

Campbell, M. \& Cueva, J. E. (1995). Psychopharmacology in child and adolescent psychiatry: A review of the past seven years. Part II. Journal of the American Academy of Child and Adolescent Psychiatry, 34, 1262-1272.

Capaldi, D. \& Patterson, G. R. (1987). An approach to the problem of recruitment and retention rates for longitudinal research. Behavioral Assessment, 9, 169-187.

Cooper, J. O., Heron, T. E. \& Heward, W. L. (1987). Applied behavior analysis. Columbus, $\mathrm{OH}$ : Merrill.

Crick, N. R. \& Dodge, K. A. (1994). A review and reformulation of social information processing mechanisms in children's social adjustment. Psychological Bulletin, 115, 74-101.

Cueva, J. E., Overall, J. E., Small, A. M., Armenteros, J. L., Perry, R. \& Campbell, M. (1996). Carbamazepine in aggressive children with conduct disorder: A double-blind and placebo controlled study. Journal of the American Academy of Child and Adolescent Psychiatry, 35, 480-490.

Cunningham, C. E., Bremner, R. \& Boyle, M. (1995). Large group community-based parenting programs for families of 
preschoolers at risk for disruptive behaviour disorders: Utilization, cost effectiveness, and outcome. Journal of Child Psychology and Psychiatry, 36, 1141-1159.

Dadds, M. R. \& McHugh, T. A. (1992). Social support and treatment outcome in behavioral family therapy for child conduct problems. Journal of Consulting and Clinical Psychology, 60, 252-259.

Dadds, M. R., Schwartz, S. \& Sanders, M. R. (1987). Marital discord and treatment outcome in behavioral treatment of child conduct disorders. Journal of Consulting and Clinical Psychology, 55, 396-403.

Dishion, T. J. \& Andrews, D. W. (1995). Preventing escalation in problem behaviors with high-risk young adolescents: Immediate and 1-year outcomes. Journal of Consulting and Clinical Psychology, 63, 538-548.

Dishion, T. J. \& Patterson, G. R. (1992). Age effects in parent training outcomes. Behavior Therapy, 23, 719-729.

Dishion, T. J., Patterson, G. R. \& Kavanagh, K. A. (1992). An experimental test of the coercion model: Linking theory, measurement, and intervention. In J. McCord \& R. E. Tremblay (Eds.), Preventing antisocial behavior (pp. 253282). New York: Guilford.

Dumas, J. E. (1989). Treating antisocial behavior in children: Child and family approaches. Clinical Psychology Review, 9, 197-222.

Dumas, J. E. \& Wahler, R. G. (1983). Predictors of treatment outcome in parent training: Mother insularity and socioeconomic disadvantage. Behavioral Assessment, 5, 301-313.

Durlak, J. A., Fuhrman, T. \& Lampman, C. (1991). Effectiveness of cognitive-behavioral therapy for maladapting children: A meta-analysis. Psychological Bulletin, 110, 204-214.

Falloon, I. R. (1988). Expressed emotion: Current status. Psychological Medicine, 18, 269-274.

Feindler, E. L. \& Ecton, R. B. (1986). Adolescent anger control: Cognitive-behavioral techniques. Elmsford, NY: Pergamon.

Feldman, R. A., Caplinger, T. E. \& Wodarski, J. S. (1983). The St. Louis conundrum: The effective treatment of antisocial youths. Englewood Cliffs, NJ : Prentice-Hall.

Fergusson, D. M., Horwood, L. J. \& Lloyd, M. (1991). Confirmatory factor models of attention deficit and conduct disorder. Journal of Child Psychology and Psychiatry, 32, 257-274.

Finch, A. J., Jr., Nelson, W. M. \& Ott, E. S. (1983). Cognitivebehavioral procedures with children and adolescents: A practical guide. Needham Heights, MA: Allyn \& Bacon.

Forehand, R. \& Long, N. (1988). Outpatient treatment of the acting out child: Procedures, long-term follow-up data, and clinical problems. Advances in Behaviour Research and Therapy, 10, 129-177.

Forehand, R. \& McMahon, R. J. (1981). Helping the noncompliant child: A clinician's guide to parent training. New York: Guilford.

Griest, D. L., Forehand, R., Rogers, T., Breiner, J., Furey, W. \& Williams, C. A. (1982). Effects of parent enhancement therapy on the treatment outcome and generalization of a parent training program. Behaviour Research and Therapy, $20,429-436$.

Henggeler, S. W. (1994). Treatment manual for family preservation using multisystemic therapy. Charleston, SC: Medical University of South Carolina, South Carolina Health and Human Services Finance Commission.

Henggeler, S. W. \& Borduin, C. M. (1990). Family therapy and beyond: A multisystemic approach to teaching the behavior problems of children and adolescents. Pacific Grove, CA: Brooks/Cole.

Henggeler, S. W., Melton, G. B. \& Smith, L. A. (1992). Family preservation using multisystemic therapy: An effective alternative to incarcerating serious juvenile offenders. Journal of Consulting and Clinical Psychology, 60, 953-961.
Henggeler, S. W., Rodick, J. D., Borduin, C. M., Hanson, C. L., Watson, S. M. \& Urey, J. R. (1986). Multisystemic treatment of juvenile offenders: Effects on adolescent behavior and family interaction. Developmental Psychology, 22, 132-141.

Henggeler, S. W., Schoenwald, S. K. \& Pickrel, S. A. G. (1995). Multisystemic therapy: Bridging the gap between universityand community-based treatment. Journal of Consulting and Clinical Psychology, 63, 709-717.

Hinshaw, S. P. (1994). Attention deficits and hyperactivity in children. Thousand Oaks, CA: Sage.

Hinshaw, S. P., Lahey, B. B. \& Hart, E. L. (1993). Issues of taxonomy and comorbidity in the development of conduct disorder. Development and Psychopathology, 5, 31-49.

Holmes, D. S. \& Urie, R. G. (1975). Effects of preparing children for psychotherapy. Journal of Consulting and Clinical Psychology, 43, 311-318.

Kaminer, Y., Tarter, R. E., Bukstein, O. G. \& Kabene, M. (1992). Comparison between treatment completers and noncompleters among dually diagnosed substance-abusing adolescents. Journal of the American Academy of Child and Adolescent Psychiatry, 31, 1046-1049.

Kazdin, A. E. (1985). Treatment of antisocial behavior in children and adolescents. Homewood, IL: Dorsey Press.

Kazdin, A. E. (1988). Child psychotherapy: Developing and identifying effective treatments. Needham Heights, MA: Allyn \& Bacon.

Kazdin, A. E. (1990). Premature termination from treatment among children referred for antisocial behavior. Journal of Child Psychology and Psychiatry, 3, 415-425.

Kazdin, A. E. (1992). Research design in clinical psychology (2nd edn.). Needham Heights, MA: Allyn \& Bacon.

Kazdin, A. E. (1993). Treatment of conduct disorder: Progress and directions in psychotherapy research. Development and Psychopathology, 5, 277-310.

Kazdin, A. E. (1994a). Behavior modification in applied settings (5th edn.). Pacific Grove, CA: Brooks/Cole.

Kazdin, A. E. (1994b). Psychotherapy for children and adolescents. In A. E. Bergin \& S. L. Garfield (Eds.), Handbook of psychotherapy and behavior change (4th edn.) (pp. 543-594). New York: Wiley \& Sons.

Kazdin, A. E. (1995a). Child, parent, and family dysfunction as predictors of outcome in cognitive-behavioral treatment of antisocial children. Behaviour Research and Therapy, 33, 271-281.

Kazdin, A. E. (1995b). Conduct disorder in childhood and adolescence (2nd edn). Thousand Oaks, CA: Sage.

Kazdin, A. E. (1996a). Combined and multimodal treatments in child and adolescent psychotherapy: Issues, challenges, and research directions. Clinical Psychology: Science and Practice, 3, 69-100.

Kazdin, A. E. (1996b). Dropping out of child psychotherapy: Issues for research and implications for practice. Clinical Child Psychology and Psychiatry, 1, 133-156.

Kazdin, A. E., Bass, D., Ayers, W. A. \& Rodgers, A. (1990a). Empirical and clinical focus of child and adolescent psychotherapy research. Journal of Consulting and Clinical Psychology, 58, 729-740.

Kazdin, A. E., Bass, D., Siegel, T. \& Thomas, C. (1989). Cognitive-behavioral treatment and relationship therapy in the treatment of children referred for antisocial behavior. Journal of Consulting and Clinical Psychology, 57, 522-535.

Kazdin, A. E. \& Crowley, M. (in press). Moderators of treatment outcome in cognitively based treatment of antisocial children. Cognitive Therapy and Research.

Kazdin, A. E., Esveldt-Dawson, K., French, N. H. \& Unis, A. S. (1987a). Problem-solving skills training and relationship therapy in the treatment of antisocial child behavior. Journal of Consulting and Clinical Psychology, 55, 76-85. 
Kazdin, A. E., Esveldt-Dawson, K., French, N. H. \& Unis, A. S. (1987b). The effects of parent management training and problem-solving skills training combined in the treatment of antisocial child behavior. Journal of the American Academy of Child and Adolescent Psychiatry, 26, 416-424.

Kazdin, A. E., Mazurick, J. L. \& Bass, D. (1993). Risk for attrition in treatment of antisocial children and families. Journal of Clinical Child Psychology, 22, 2-16.

Kazdin, A. E., Mazurick, J. L. \& Siegel, T. C. (1994). Treatment outcome among children with externalizing disorder who terminate prematurely versus those who complete psychotherapy. Journal of the American Academy of Child and Adolescent Psychiatry, 33, 549-557.

Kazdin, A. E., Siegel, T. C. \& Bass, D. (1990b). Drawing upon clinical practice to inform research on child and adolescent psychotherapy: A survey of practitioners. Professional Psychology: Research and Practice, 21, 189-198.

Kazdin, A. E., Siegel, T. \& Bass, D. (1992). Cognitive problemsolving skills training and parent management training in the treatment of antisocial behavior in children. Journal of Consulting and Clinical Psychology, 60, 733-747.

Kendall, P. C. (Ed.) (1991). Child and adolescent therapy: Cognitive-behavioral procedures. New York: Guilford.

Kiesler, D. J. (1971). Experimental designs in psychotherapy research. In A. E. Bergin \& S. L. Garfield (Eds.), Handbook of psychotherapy and behavior change: An empirical analysis (pp. 36-74). New York: Wiley.

Kupfer, D. J., Frank, E., Perel, J. M., Cornes, C., Mallinger, A. G., Thase, M. E., McEachran, A. B. \& Grochocinski, V. J. (1992). Five-year outcome for maintenance therapies in recurrent depression. Archives of General Psychiatry, 49, 769-773.

Lochman, J. E. \& Dodge, K. A. (1994). Social-cognitive processes of severely violent, moderately aggressive, and nonaggressive boys. Journal of Consulting and Clinical Psychology, 62, 366-374.

Long, P., Forehand, R., Wierson, M. \& Morgan, A. (1994). Does parent training with young noncompliant children have long-term effects? Behaviour Research and Therapy, 32, 101-107.

Lundman, R. J. (1984). Prevention and control of juvenile delinquency. New York: Oxford University Press.

Lytton, H. (1990). Child and parent effects in boys' conduct disorder: A reinterpretation. Developmental Psychology, 26, 683-697.

Mann, B. J., Borduin, C. M., Henggeler, S. W. \& Blaske, D. M. (1990). An investigation of systemic conceptualizations of parent-child coalitions and symptom change. Journal of Consulting and Clinical Psychology, 58, 336-344.

McMahon, R. J., Forehand, R., Griest, D. L. \& Wells, K. C (1981). Who drops out of treatment during parent behavioral training? Behavioral Counseling Quarterly, 1, 79-85.

McMahon, R. J. \& Wells, K. C. (1989). Conduct disorders. In E. J. Mash \& R. A. Barkley (Eds.), Treatment of childhood disorders (pp. 73-132). New York: Guilford Press

Miller, G. E. \& Prinz, R. J. (1990). Enhancement of social learning family interventions for child conduct disorder. Psychological Bulletin, 108, 291-307.

Moffitt, T. E. (1993). The neuropsychology of conduct problems. Development and Psychopathology, 5, 135-151.

Morris, S. M., Alexander, J. F. \& Turner, C. W. (1991). Do reattributions reduce blame? Journal of Family Psychology, $5,192-203$.

Newberry, A. M., Alexander, J. F. \& Turner, C. W. (1991). Gender as a process variable in family therapy. Journal of Family Psychology, 5, 158-175.

O'Donnell, C. R. (1992). The interplay of theory and practice in delinquency prevention: From behavior modification to activity settings. In J. McCord \& R. E. Tremblay (Eds.),
Preventing antisocial behavior (pp. 209-232). New York: Guilford.

Offord, D. R., Boyle, M. H. \& Racine, Y. A. (1991). The epidemiology of antisocial behavior. In D. J. Pepler \& K. H. Rubin (Eds.), The development and treatment of childhood aggression (pp. 31-54). Hillsdale, NJ : Erlbaum.

Patterson, G. R. (1982). Coercive family process. Eugene, OR: Castalia.

Patterson, G. R., Capaldi, D. \& Bank, L. (1991). An early starter model for predicting delinquency. In D. J. Pepler \& K. H. Rubin (Eds.). The development and treatment of childhood aggression (pp. 139-168). Hillsdale, NJ : Erlbaum.

Patterson, G. R. \& Chamberlain, P. (1994). A functional analysis of resistance during parent training therapy. Clinical Psychology: Science and Practice, 1, 53-70.

Patterson, G. R., DeBaryshe, B. D. \& Ramsey, E. (1989). A developmental perspective on antisocial behavior. American Psychologist, 44, 329-335.

Patterson, G. R., Dishion, T. J. \& Chamberlain, P. (1993). Outcomes and methodological issues relating to treatment of antisocial children. In T. R. Giles (Ed.), Handbook of effective psychotherapy (pp. 43-87). New York: Plenum.

Patterson, G. R., Reid, J. B. \& Dishion, T. J. (1992). Antisocial boys. Eugene, OR: Castalia

Pepler, D. J. \& Rubin, K. H. (Eds.) (1991). The development and treatment of childhood aggression. Hillsdale, NJ : Erlbaum.

Prinz, R. J. \& Miller, G. E. (1994). Family-based treatment for childhood antisocial behavior: Experimental influences on dropout and engagement. Journal of Consulting and Clinical Psychology, 62, 645-650.

Robins, L. N. (1981). Epidemiological approaches to natural history research: Antisocial disorders in children. Journal of the American Academy of Child Psychiatry, 20, 566-680.

Robins, L. N. (1991). Conduct disorder. Journal of Child Psychology and Psychiatry, 32, 193-212.

Rubin, K. H., Bream, L. A. \& Rose-Krasnor, L. (1991). Social problem solving and aggression in childhood. In D. J. Pepler \& K. H. Rubin (Eds.), The development and treatment of childhood aggression (pp. 219-248). Hillsdale, NJ : Erlbaum.

Rutter, M.\& Giller, H. (1983). Juvenile delinquency: Trends and perspectives. New York: Penguin Books.

Sanders, M. R. \& Dadds, M. R. (1993). Behavioral family intervention. Needham Heights, MA: Allyn \& Bacon.

Santisteban, D.A, Szapocznik, J., Perez-Vidal, A., Kurtines, W. H., Murray, E. J. \& LaPerriere, A. (1996). Efficacy of intervention for engaging youth and families into treatment and some variables that may contribute to differential effectiveness. Journal of Family Psychology, 10, 35-44.

Shirk, S. R. (Ed.) (1988). Cognitive development and child psychotherapy. New York: Plenum.

Shure, M. B. (1992). I can problem solve (ICPS): An interpersonal cognitive problem solving program. Champaign, IL: Research Press.

Spivack, G. \& Shure, M. B. (1982). The cognition of social adjustment: Interpersonal cognitive problem solving thinking. In B. B. Lahey \& A. E. Kazdin (Eds.), Advances in clinical child psychology, Vol. 5 (pp. 323-372). New York: Plenum.

Stewart, J. T., Myers, W. C., Burket, R. C. \& Lyles, W. B. (1990). A review of the psychopharmacology of aggression in children and adolescents. Journal of the American Academy of Child and Adolescent Psychiatry, 29, 269-277.

Szapocznik, J., Perez-Vidal, A., Brickman, A., Foote, F. H., Santisteban, D., Hervis, O. \& Kurtines, W. H. (1988). Engaging adolescent drug abusers and their families into treatment: A strategic structural systems approach. Journal of Consulting and Clinical Psychology, 56, 552-557.

Szapocznik, J., Rio, A., Murray, E., Cohen, R., Scopetta, M., Rivas-Vasquez, A., Hervis, O., Posada, V. \& Kurtines, W. 
(1989). Structural family versus psychodynamic child therapy for problematic Hispanic boys. Journal of Consulting and Clinical Psychology, 57, 571-578.

United States Congress, Office of Technology Assessment. (1991). Adolescent health. (OTA-H-468). Washington, DC: U.S. Government Printing Office.

Wahler, R. G. \& Dumas, J. E. (1986). Maintenance factors in coercive mother-child interactions: The compliance and predictability hypotheses. Journal of Applied Behavior Analysis, 19, 13-22.

Walker, J. L., Lahey, B. B., Russo, M. F., Christ, M. A. G., McBurnett, K., Loeber, R., Stouthamer-Loeber, M. \& Green, S. M. (1991). Anxiety, inhibition, and conduct disorder in children: I. Relation to social impairment. Journal of the American Academy of Child and Adolescent Psychiatry, 30, 187-191.

Webster-Stratton, C. (1985). Predictors of treatment outcome in parent training for conduct disordered children. Behavior Therapy, 16, 223-243.
Webster-Stratton, C. (1994). Advancing videotape parent training: A comparison study. Journal of Consulting and Clinical Psychology, 62, 583-593.

Webster-Stratton, C., Hollinsworth, T. \& Kolpacoff, M. (1989). The long-term effectiveness and clinical significance of three cost-effective training programs for families with conductproblem children. Journal of Consulting and Clinical Psychology, 57, 550-553.

Wierzbicki, M. \& Pekarik, G. (1993). A meta-analysis of psychotherapy dropout. Professional Psychology: Research and Practice, 24, 190-195.

Weisz, J. R., Walter, B. R., Weiss, B., Fernandez, G. A. \& Mikow, V. A. (1990). Arrests among emotionally disturbed violent and assaultive individuals following minimal versus lengthy intervention through North Carolina's Willie $\mathbf{M}$. Program. Journal of Consulting and Clinical Psychology, 58, 720-728.

Accepted manuscript received 19 May 1996 